Florida International University FIU Digital Commons

11-28-1994

\title{
Occupational therapists as consultants in Florida schools : a survey
}

Leigh Ann Agee

Florida International University

DOI: $10.25148 /$ etd.FI13101537

Follow this and additional works at: https://digitalcommons.fiu.edu/etd

Part of the Occupational Therapy Commons

\section{Recommended Citation}

Agee, Leigh Ann, "Occupational therapists as consultants in Florida schools : a survey" (1994). FIU Electronic Theses and Dissertations. 1139.

https://digitalcommons.fiu.edu/etd/1139

This work is brought to you for free and open access by the University Graduate School at FIU Digital Commons. It has been accepted for inclusion in FIU Electronic Theses and Dissertations by an authorized administrator of FIU Digital Commons. For more information, please contact dcc@fiu.edu. 


\title{
FLORIDA INTERNATIONAL UNIVERSITY
}

\author{
Miami, Florida \\ OCCUPATIONAL THERAPISTS AS CONSULTANTS IN \\ FLORIDA SCHOOLS: A SURVEY
}

\begin{abstract}
A thesis submitted in partial satisfaction of the requirements for the degree of MASTER OF SCIENCE
\end{abstract}

IN

OCCUPATIONAL THERAPY

by

Leigh Ann Agee

1994 
To:

Dr. Judith Blucker

College of Health

This thesis, written by Leigh Ann Agee, and entitled Occupational

Therapists as Consultants in Florida Schools: A Survey, having been approved in respect to style and intellectual content, is referred to you for judgement.

We have read this thesis and recommend that it be approved.

Susan Kaplan

Michael Brady

Sharon Lefkofsky, Major Professor

Date of Defense: November 28, 1994

The thesis of Leigh Ann Agee is approved.

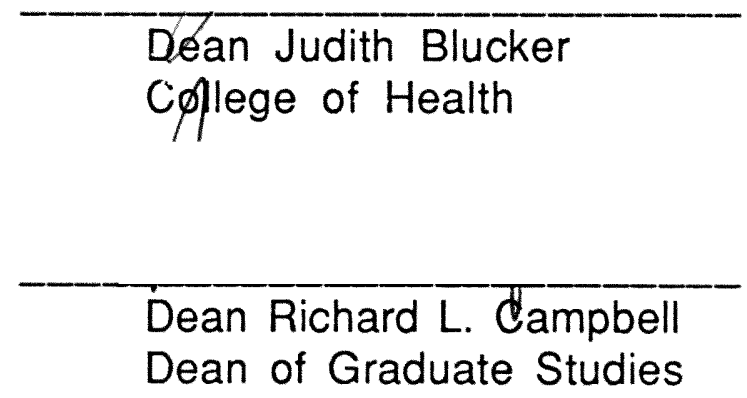

Florida International University, 1994 


\section{ACKNOWLEDGEMENTS}

I wish to thank the members of my committee for their helpful comments and patience. I also want to thank Dr. Jyoti Zalkikar for her help with the statistical analysis of the study.

A special thanks must go to my family and friends for their support and encouragement. Without their confidence in me, this project would never have been completed. 


\section{ABSTRACT OF THE THESIS}

OCCUPATIONAL THERAPISTS AS CONSULTANTS

IN FLORIDA SCHOOLS: A SURVEY

by

Leigh Ann Agee

Florida International University, 1994

Miami, Florida

Professor Sharon Lefkofsky, Major Professor

Little research has been done on how well prepared occupational therapists feel to perform the role of consultant. This study investigated the perceptions of occupational therapists acting as consultants in Florida schools, how much education/training they have received and how they perceive their consultation skills. Participants in the study were sent a questionnaire and measures of central tendency were calculated on each item. Crosstabulations using Fisher's exact test were completed to investigate any relationship between type of consultation model used and relationships with educators. A one way ANOVA was conducted to investigate any relationship between self-perceived consultant skills and age, amount of experience, and training. The results indicate that occupational therapists providing consultative services rate their abilities as more than adequate and believe formal training in consultation is only mildly important. No significant relationships were found between training and skills or model used and relationships with educators. 


\section{TABLE OF CONTENTS}

CHAPTER

PAGE

I. INTRODUCTION

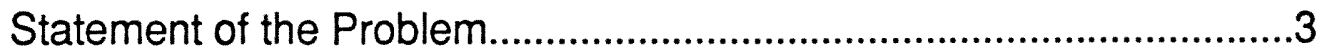

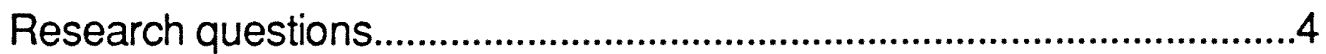

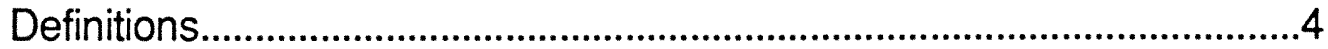

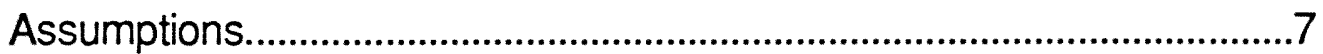

\section{LITERATURE REVIEW}

Occupational Therapy in the Schools...........................................9

General Consultation Theory.......................................................14

OT Consultation Theory......................................................................15

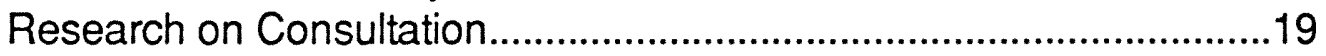

Collaborative Consultation.............................................................22

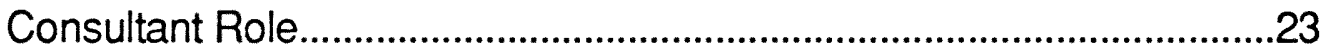

Consultation as an Alternative to Direct Service....................24

Training/Preparedness for Consultation...................................25

Relationship Between OTs and School Personnel......................29

III. METHODOLOGY

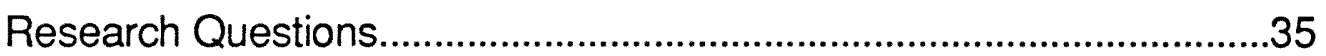

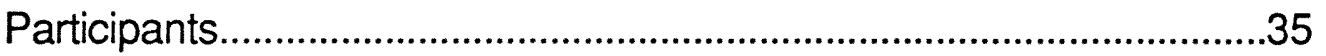

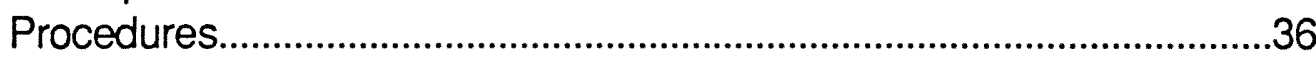

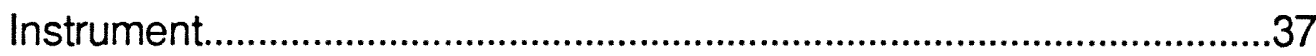

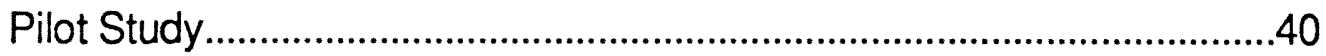

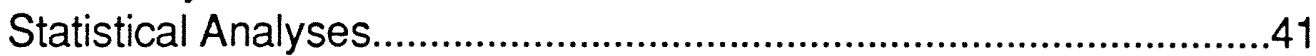

Limitations of the Study...............................................................42

IV. RESULTS

Demographics........................................................................................43

Amount of time spent/preferred in consultation...................44

Recipients of consultative services........................................44

Service delivery options...............................................................45

Model of consultation used/preferred.....................................45 
Perceived relationships with educators.................................45

Perceived barriers to the consultation process.....................46

Perceived benefits of the consultation process......................47

Roles assumed while consulting................................................47

Motivators for engaging in consultation................................47

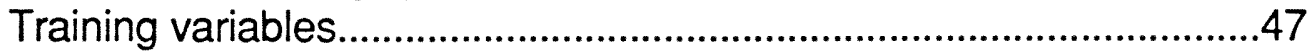

Perceived importance of background/knowledge in

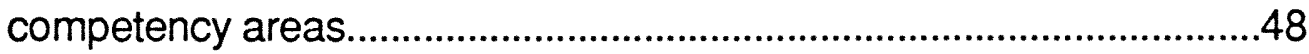

Self-perceived consultation skills............................................49

Correlations between use of service models and

perceived relationships with educators...................................49

Correlations between demographics and training ..................50

\section{DISCUSSION}

Conclusions. 52

Recommendations for Future Research....................................58

Summary.

VI. REFERENCES.

VII. TABLES

VII. APPENDICES

A- Survey of occupational therapists employed by

Florida schools

B- Survey Cover Letter. 


\section{LIST OF TABLES}

Number

1 Participant Demographics.....................................................................69

2 Participant Demographics..........................................................................70

3 Occupational Therapists' Actual and Preferred Time Spent in Consultative Services................................................................................71

4 With Whom do Respondents Consult and How Often...........................72

5 Primary Model of Consultation Used and Preferred by Respondents.

6 Occupational Therapists' Ratings of Relationships with

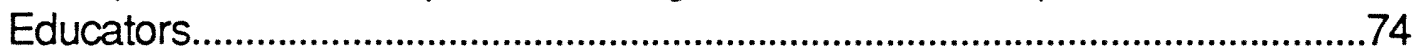

7 Perceived Barriers to the Consultation Process................................75

8 Perceived Benefits of the Consultation Process................................76

9 Roles Occupational Therapists Assume When Consulting................77

10 OT Respondents' Motivators for Engaging in Collaborative Consultation..............................................................................................78

11 Training Received by Occupational Therapists....................................79

12 Occupational Therapists' Perceived Importance of Various Areas of Knowledge to Perform Consultation......................................8

13 Self-Perceived Consultation Skills.....................................................81

14 Correlations Between Consultation Models Used and Perceived Relationships with Educators..................................................................82 


\section{Chapter 1}

\section{Introduction}

Over 10,000 occupational therapists (OTs) are currently employed by public school systems in the United States. The enactment of Public Law 94-142, the Education for all Handicapped Children Act of 1975, greatly expanded public education opportunities for students with disabilities. Under Part B of this Act occupational therapy (OT) is included as one of the related services to be received by the child. Because of this, the need for occupational therapists in school systems has grown rapidly.

Occupational therapy is the art and science of directing man's participation in selected tasks to restore, reinforce and enhance performance, facilitate learning of those skills and functions essential for adaptation and productivity, diminish or correct pathology, and to promote and maintain health (Hopkins, 1988). The occupational therapist's role in the school setting is to facilitate competencies that will help the child benefit from the total educational experience (Kaufmann, 1987).

Occupational therapists play an integral role in the interdisciplinary team that serves children with disabilities. Services provided are from one of three models: direct service, monitoring, or consultation (Idol \& West, 1987). 
Consultation is the model that therapists know the least about but is growing steadily in popularity (Dunn, 1990). In this model the therapist provides indirect service to the child by collaborating directly with the teacher. The two, as well as any other team members, collaborate to establish mutually defined problems, intervention strategies, and goals for each individual child. The teacher is then responsible for implementing the program with continual suggestions and monitoring by the therapist (Dunn, 1990). The theoretical concepts of consultation are congruent with the concepts and principles of occupational therapy and as a service provision, consultation works well with the occupational therapist's holistic view of the child (Jaffe, 1992a).

In the future, the need for occupational therapists in schools is likely to continue and the need may increase. Providing consultative services is one way in which occupational therapists can meet the high demand for services and also assist teachers in the mainstreaming process. To provide this service, however, occupational therapy as a profession must ensure that therapists are prepared and willing to assume the role of consultant. The purpose of this study is to determine OTs' preparation to do consultation and to assess how many therapists are currently providing the service, how much consultation training they have had, and how they perceive their own skills as consultants. 


\section{Statement of the Problem}

If occupational therapists are performing the role of consultant within the school system, it is important to investigate how ready and willing they are to perform this role. To do this the profession must look at the attitudes and perceptions of its therapists, how much education and training they have received to provide this service, and how they perceive their own consultation skills or competencies. Little research has been done on occupational therapists as school consultants, and many occupational therapists have never been prepared nor prepared themselves before taking on this role. For an occupational therapist to be competent in providing consultation services and to be able to define their roles for educators, certain competencies are needed. Therefore, a study is needed to determine whether OTs possess the skills and competencies needed to assume this role, and what their attitudes are concerning this position in schools.

The need for occupational therapists in the schools is growing as the number of children needing special education and related services steadily increases. How occupational therapists perceive their own skills and competence in this area is an important first step in determining if additional training is necessary to prepare therapists and other health care personnel for this role. 


\section{Research Questions}

1. Do occupational therapists believe they possess the competencies needed to provide collaborative consultative services within the schools?

2. With whom do occupational therapists engage in school consultations, how often, and how do they view these relationships?

3. How much training and/or education have occupational therapists received on how to be an effective consultant?

4. What are the perceived barriers and perceived benefits to the consultative process within school systems?

5. How do experience, training, age, and highest degree relate to self-perceived consultant skills in occupational therapists?

\section{Definitions}

Collaborative consultation- An interactive process that acknowledges the specialized expertise of both the consultant and consultee making up the interactive team, and shares the responsibility for identifying a problem and generating a solution. The outcome is enhanced and altered from the original solutions that any team member would produce independently. It is an indirect process. Although the team develops the intervention plan, only one member of the team is responsible for implementation of the plan (Dunn \& Campbell, 1991).

Consultant- a professional who provides indirect service to a 
consultee or to a client through someone else (in this study, the occupational therapist) (Dunn \& Campbell, 1991).

Consultee- the individual, organization, or part of an organization or system that is seeking help with defining or solving a current or potential problem (in this study, the teacher or educational personnel).

Client- the recipient of the consultee/consultant services Competencies for consultation- Based on the theory and principles of consultation there are certain personality traits, attitudes, and attributes basic to the successful consultant (professionalism, maturity, credibility, personableness, honesty, flexibility, creativity, objectivity, intelligence, insight, selfmotivation); necessary knowledge and skills in three major areasinterpersonal skills, technical skills, consulting skills; and education and training necessary to practice as a consultant.

Direct therapy- the intervention activities that are individually designed, and are carried out specifically by the therapist and one child, or the therapist and a small group of children (Dunn, 1989).

Monitoring- the therapist conducts an assessment to identify the child's strengths/needs and then designs an intervention plan to meet the needs and remains responsible for the outcome (Dunn, 1989). 
Occupational therapy services within the school systemservice provided by a licensed or certified OT to address the functional needs of a child related to performance of self-help skills, adaptive behavior and play, and sensory, motor, postural, and emotional development. These services are designed to help families and other care givers increase the child's functioning in school, home, and community settings through identification, referral, assessment, intervention, and consultation. (Chandler, Dunn, \& Rourk, 1989).

Occupational therapist- an individual who is trained and licensed to perform occupational therapy

Perceived barriers to the consultation process- those factors that occupational therapists believe in some way impede the consultation process

Perceived benefits of the consultation process- those items that occupational therapists believe are enhanced or promoted as a result of the consultation process

Self-perceived consultant skills- the way occupational therapists rate their own skills in the area of consultation Training and/or education in consultation- the formal or informal preparation received by occupational therapists in the area of consultation

The Education of All Handicapped Children Act of 1975 (P.L. 94-142) The federal statute that states as one of its central 
provisions that all children with disabilities are entitled to a free and appropriate public education designed to meet their unique needs (Heron \& Harris, 1987).

The Education of the Handicapped Act (EHA) amendments (P.L. 99-457) The federal statute that extends mandated services to infants, toddlers, preschoolers and their families, and specifies a family-focused referral process (Merryfield, 1992).

School Consultation- Consultative services in which OTs use their professional skills in early intervention and school programs to enable parents, teachers, other professionals, and extended family members to become more effective at dealing with their children's needs (Dunn, 1992).

\section{Assumptions}

1. Occupational therapists are providing consultative services to school personnel and students using the indirect service model approach.

2. Occupational therapists responding to the current study are providing consultative services to school personnel and students as defined in this study.

3. Educational personnel do not fully understand the role of occupational therapists in schools, and occupational therapists do not fully understand the teachers' role with children with disabilities, which impedes the consultative process. 
4. The majority of occupational therapists have not been formally trained on how to provide effective consultative services.

5. The respondents of the survey will answer the questions openly and honestly.

6. The responses obtained from the survey will answer the research questions. 
Chapter 2

\section{Literature Review}

Most of the literature on consultation is from the medical, mental health and business professions. Very few studies have been done on consultation related to occupational therapy specifically. The nature of OT in pediatric services and in the schools, however, has been widely discussed. This literature was greatly expanded after the enactment of PL 94-142, and continues to be the focus of literature as an area continuing to expand for OTs in pediatrics.

\section{Occupational therapy in the schools}

By the early 1970's a great deal of concern regarding educational opportunities for children with disabilities had developed (Colman, 1988). By 1975 a group of teachers, parents, administrators, and advocates were lobbying at the federal level for a provision of services by a number of professionals to meet the needs of children with disabilities (Colman, 1988). The enactment of The Education of all Handicapped Children Act (EHA) of 1975 (PL 94-142), and its amendments to include handicapped infants, toddlers, and preschoolers (PL 99-457,1986), created a large influx of occupational therapists (OTs) into the public schools (Heron \& Harris, 1987). Occupational therapy (OT) is included in these mandates as a related service to be provided as necessary so a student may benefit from the special education program (Chandler, 
Dunn, \& Rourk, 1989). As an education-related service, occupational therapy can only be provided to students who have been identified as handicapped under the definitions within the EHA and who need special education (Chandler, Dunn, \& Rourk, 1989). While the EHA mandates the provision of a free, appropriate public education to all children who are disabled, regardless of the severity of the disabling condition (Coutinho \& Hunter, 1988), only those problems that affect learning may be addressed as part of the educational program (Dunn, 1989). The EHA mandates that children receive services in the least restrictive environment possible (Coutinho \& Hunter, 1988). This environment is often the child's regular classroom setting.

As OT practice moved from the medical model to the educational model in the school system, philosophical shifts had to be made as well. OT personnel must function in a collaborative style which necessitates the sharing of knowledge and responsibilities with educational personnel (Chandler, Dunn, \& Rourk, 1989).

Although the number of available positions for occupational therapists increased steadily after the laws went into effect, there were not sufficient numbers of occupational therapists with the needed specialized training to meet the needs of school-based programs (Gilfoyle \& Hays, 1979). Recognizing this, the American Occupational Therapy Association developed the "Advanced Training for Occupational Therapists in School Systems" in 1978. This was 
designed to identify therapists' roles and functions, specification of competencies required to meet those roles and functions, and the development of competency-based education programs designed for the acquisition of those competencies (Gilfoyle \& Hays, 1979). The philosophical base of this therapy program was to use purposeful activity and encourage students to continually adapt to more challenging learning experiences, while remembering that the context must be the educational environment. The therapy program was designed to assist the development of underlying skills that are prerequisites for academic learning and vocational training (Chandler, Dunn, \& Rourk, 1989).

Roles of OTs. As a member of the interdisciplinary education team, an occupational therapist has four primary roles: assessment, program planning, intervention, and management of the OT program (Chandler, Dunn, \& Rourk, 1989). Assessment includes screening, evaluation, and reassessment. Program planning includes developing the Individual Education Program (IEP) and OT intervention plan to address specific problems as identified through assessment. Intervention includes all activites performed by the OT to implement the treatment plan. Management of the program includes planning, developing, implementing, and evaluating the OT program (Chandler, Dunn, \& Rourk, 1989). All of these roles begin once the child has been referred for OT services. 
Referral. School-aged children are usually referred for OT services by school personnel when dysfunction interferes with the learning process. The referral process is very important because it is the starting point for the process of providing pediatric services (Merryfield, 1991).

Screening. Routine screening may be done by teachers prior to referral or by OTs as the first part of the evaluation to verify if a child needs further diagnostic evaluation (Collier, 1991). Screening involves looking at a child's skills in a general, more broad sense to determine if they are within normal developmental expectations for children of the same age (Collier, 1991).

Assessment. The assessment is a comprehensive process of obtaining information about an individual and family, gathered from several sources, and reported in an objective manner. The assessment identifies concerns or weaknesses while also identifying strengths (Cook, 1991).

OT and the interdisciplinary team. In the school environment the OT is part of an interdisciplinary team. This team meets after each discipline performs an initial assessment to determine if a child is disabled and in need of special education. A child's complex nature can be more successfully understood and his needs more adequately addressed when a group of professionals bring together their areas of expertise to identify an accurate diagnosis and design an effective intervention strategy (Cook, 1991). 
Interdisciplinary program planning. If the team decides that the child requires OT as part of the specialized education program, the OT must provide the team with the recommendations based on appropriate assessment procedures in a form that is comprehensible to other team members (Coutinho \& Hunter, 1988) and in an educational context (Royeen \& Marsh, 1988). The team translates the recommendations into an IEP for each child and compares service models to decide how the intervention will occur and be coordinated (McCormick \& Lee, 1979). The primary team structure within the schools is integrated services, which uses the therapeutic expertise of each member to address the child's needs within his natural life environments (Muhlenhaupt, 1991).

Service delivery models. There are three major service models used in the schools to administer services to children (Dunn, 1989). These are: direct service, monitoring, and consultation. In direct service, occupational therapy practitioners use specific techniques and approaches with one student or a small group of students. Generally the therapist has frequent contact with them several times a week.

In monitoring, the therapist supervises specifically designed intervention as carried out by others in the context of other learning activities. 
In consultation therapists collaborate with team members and specialized expertise is used to facilitate the workings of the educational system (Dunn, 1988).

The therapist should choose the model based on what is best suited to meet the needs of the child (Muhlenhaupt, 1991), and the intervention must be planned and provided within the child's least restrictive environment (Chandler, Dunn, \& Rourk, 1989). This is usually the child's classroom or home since the purpose is to improve the child's ability to function in his natural environments (Dunn \& Campbell, 1991).

Evidence is accumulating to demonstrate that each model is effective when chosen and applied appropriately (Dunn, 1988), and often more than one type of service provision is preferable for generalization of learning to many environments (Dunn \& Campbell, 1991). Three issues must be considered when deciding which service provision to use: the overall purpose of the intervention, which model will best address needs, and the location of the services to be provided (Dunn \& Campbell, 1991).

\section{General Consultation Theory}

Consultation is an indirect service method designed to enable others to meet their expressed goals and is the more effective choice for situations requiring generalizability of skills to life demands, and/or adaptation of tasks or materials (Dunn, 1992). 
Consultation can be oriented toward student needs, professional needs, or system needs. It is imperative that OTs direct themselves to these needs in order to be most effective in the educational setting (Chandler, Dunn, \& Rourk, 1989). The consultant can work individually with a student, teacher, or administrator to change their behavior, or indirectly with a mediator to change the behavior of a third party (Heron and Harris, 1987).

Most of the literature, theory, and models reviewed related to consultation focus on the relationship between the consultant and consultee. This relationship should not be considered linear, but triadic, as there are occassions when the consultant's direct access to the client or client system is extremely useful in data gathering, system analysis, problem definition, activities, intervention and evaluation (Kurpius \& Fuqua, 1993). In a school context, the consultative triad may involve any special education teacher or consultant interacting in a professional relationship with a regular classroom teacher (consultee) on a matter related to a targeted student (the client) for whom the regular classroom teacher has primary responsibility (West \& Idol, 1987).

\section{OT Consultation Theory}

Consultation is the model that is least known to therapists (Dunn, 1988), and has been growing steadily in popularity in the last twenty years (Idol \& West, 1987). The first occupational therapist 
consultants were recorded in the 1950's (Jaffe \& Epstein, 1992a) and the demand for them increased with the passage of health care and educational legislation in the 1970's (PL 94-142).

Health care legislation accelerated the use of consultation services by removing architectural barriers, addressed in the Rehabilitation Act of 1973 (Jaffe \& Epstein, 1992a). A nationwide training program was also launched by the occupational therapy profession to provide effective school-based services. Therapists were involved in an indepth continuing education program and introduced to the concept of monitoring. As demands increased for school services, the need for collaborative style of consultation in schools was introduced (Jaffe \& Epstein, 1992a). Today the greatest number of OTs who are considered consultants are currently working in the public school systems (Jaffe \& Epstein, 1992a).

The nature of OT practice fosters an environment of mutual cooperation between the dysfunctional patient and therapist (Dunn, 1992). The inherent goal is to enable individuals with disabilities through increased occupational performance to function in daily life and take charge of their lives. For a child this could mean mastering their school environment.

Similarly, the nature of consultation requires an environment of mutual cooperation and collaboration between client systems and 
consultant. Enabling the client, through increased performance to create positive change and increase the organization's functional performance is the consultation goal (Jaffe \& Epstein, 1992c).

OT consultation theory has evolved from the occupational performance frame of reference and Reilly's occupational behavior perspective (Jaffe \& Epstein, 1992c). There are four major themes: humanistic roots, a preventive perspective, recognition that humankind has a need to engage in meaningful occupation within natural environments, and the importance of adaptation and the environment as organizing factors (Jaffe \& Epstein, 1992c). OTs bring to the consultative process a rich heritage of commitment to a holistic view of humans; dedication to self-care, play, work; a linkage between environment and health; the use of occupation to promote change; and the uniqueness of each individual (Gilfoyle, 1992).

Underlying the process of OT and consultation is a strong foundation in systems theory, which by definition acknowledges the integral part played by the environment (Jaffe \& Epstein, 1992c). Using extensive and intensive analysis of the environment, the therapist, as consultant, applies the principles of OT and the process of consultation to facilitate and enhance function for the client system (Jaffe \& Epstein, 1992c). The model incorporates basic OT principles, philosophical assumptions, and people's interrelationships to the environment, but the locus of control 
shifts from final decision-making by the therapist to the client and/or consultee (Jaffe \& Epstein, 1992c).

The collaborative consultation model is both a teaching and a "troubleshooting" model. The focus is on interdependence with the intention that both consultant and consultee will benefit/learn from the mutual problem solving and that each have precise, yet diverse bases of knowledge and expertise from which solutions are generated (West \& Idol, 1987). In the collaborative model, the goal is to improve understanding and skills and generalize learning to future, similar problems by collaborating with other professional colleagues. It is an interactive process enabling people with diverse professional backgrounds and expertise to produce solutions to mutually defined problems. In educational consultation, the target of services is the teacher, the goal is enhanced functional efficiency in the classroom, the means is educational consultation through skill development, and the outcome is a change in behavior (Jaffe, 1992a).

The development of a theoretical model of occupational therapy consultation will provide a base of knowledge to strengthen practice, and validate the premise that consultation is an inherent part of the occupational therapy process (Jaffe \& Epstein, 1992c). 


\section{Research on Consultation}

Most of the writing on consultation comes from the business and medical literature, or from the literature on mental health, school psychology, and organizational development (Idol \& West, 1987; West \& Idol, 1987). Alpert and Yammer (1983) believe the lack of attention to special education settings in consultation research is noteworthy since consultative activity is consistent with the intent of PL 94-142 and more research in this area is needed.

West and Idol (1987) divided research on consultation in special education and related professions into three major areas: input, process, and output variables. Most of the research on consultation has been done on output variables, which focuses on the changes, both in persons seeking consultation and in students, that are a direct result of consultation (Dunn, 1988). Only a few studies have investigated the impact of process variables on consultation outcomes (Medway, 1982), and input variables have been given a small amount of attention (West \& Idol, 1987). Input variables are the most inwardly focused variables and include the consultant's personality traits, and readiness for the consultation process. More research is needed to clarify the role that input variables play in the success of consultation (Dunn, 1988).

Jaffe and Epstein, (1992b) identified certain character/ personality traits and inherent attitudes and attributes suggested as 
basic to the successful consultant. These include professionalism, maturity, credibility, personableness, honesty and sincerity, flexibility, creativity, objectivity, intelligence, insight, and selfmotivation among others.

In Peter Block's Flawless Consultation (Ross, 1993), the authentic behavior of the consultant is identified as the single most important aspect of the consulting process. He states that the consultant must acknowledge feelings and thoughts as they surface during the consultation process in order to increase trust and commitment in the collaborative team at the earliest possible juncture.

There are certain skills seen as necessary to be an effective consultant. Jaffe and Epstein (1992b) identify three major areas of skill: interpersonal skills including the ability to establish rapport and relationships; communication skills, and counseling skills; technical skills (including for the purpose of this study, expertise in OT), specialized training, and skills in teaching, planning and intervention; and consulting skills which include knowledge of the client system, diagnosis, problem-solving skills, facilitation skills, knowledge of self, the behavioral sciences, social sciences, and the basic phases of consultation.

Knoff (1991) believes that it is the adaptation and timing of specific consultative skills to the settings where they are needed that determines consultation success or failure. He identified five 
factors that are imperative to the effectiveness of the consultant: consultation process skills, expert skills, personal characteristics, interpersonal skills, and professional respect or consultant directiveness. In a study using ratings by superiors and ratings by peers to measure the effectiveness of consultants, Hamilton (1988) examined whether personality characteristics or behavioral tendencies were prerequisite to learning of effective consultant behaviors or a result of intensive consultation training. They found both to be prerequisite and found a limitation to be the lack of client ratings, since a client's opinion as to whether an intervention succeeded is generally considered a significant measure of a consultant's effectiveness. For further research, Hamilton suggested further study of the impact of knowledge of theory and techniques on consultation effectiveness to see if this overcomes personality factors.

Costenbader, Swartz and Petrix (1992) examined consultation in the schools, specifically the relation among preservice training, perception of consultative skills, and actual time spent in consultation. They found a significant discrepancy between the actual amount of time and the preferred amount of time respondents spent in consultation and that the actual amount of time school psychology practitioners spent in consultation is not related to demographic variables, training variables, or perception of consultative skill. 


\section{Collaborative Consultation}

When teachers and other school personnel have been exposed to other models of consultation, they overwhelmingly prefer the collaborative style of consultation (Idol \& West, 1987).

In a study comparing direct service and consultation provided to preschoolers, Dunn (1990) found that both groups attained the same number of IEP goals. However, teachers who collaborated with therapists in consultation reported that OTs contributed $24 \%$ more to the attainment of IEP goals. It seems the shared responsibilities and partnership is mutually satisfying and a positive growth experience for both parties involved (Idol \& West, 1987). The collaborative consultation model forms the primary base for collaboration in the schools because of the emphasis placed on the interactive process, as well as on mutuality and reciprocity (West \& Idol, 1993). West and Idol (1993) identify three categories of expertise for collaborative consultation: the underlying knowledge base, interpersonal skills, and intrapersonal attitudes. Throughout the process, team interactions are characterized by mutual respect, trust, open communication, consideration of each issue or problem from an ecological perspective, consensual decision making, pooling personal resources and expertise, and joint ownership of the issue. 


\section{Consultant Role}

The consultant must be able to assume a variety of roles during the consultation process. There are three types of consultation that the OT might engage in. They are case consultation in which the focus is on student needs, colleague consultation which addresses the needs of other professionals in the educational environment, and system consultation which addresses the needs of the system (Chandler, Dunn, \& Campbell, 1991).

Heron and Harris (1987) describe three overlapping roles of the consultant: providing technical assistance, directly or indirectly; coordinating programs through facilitation of the IEP or managing resources such as personnel or information; and communicating with professionals. Other roles the consultant may assume during the consultation process include, but are not limited to: an adviser, facilitator, expert/information specialist, a change agent, an evaluator, a diagnostician, a trainer/educator, a planner, a collaborator, and an advocate (Epstein, 1992). Consultants typically assume multiple roles since they must react to a situation appropriately and assume one or more roles at any given time. Most important is the choice of role that is the most effective for specific clients' needs (Jaffe, 1992b).

The consultant's roles are critical since the school-based therapist may be in a program alone, have a large population to serve, and represents a relatively new profession within the 
education system. The primary goal of the consultative role is to increase the awareness of and to coordinate OT services as applied to educational priorities and programming, thus enhancing the individual's learning (Gilfoyle \& Hays, 1979). A consultant may be either internal or external to the system in which they are providing services. Since most school-based OTs are on contract they are internal consultants. The advantages of this is that they are a part of the system and know the internal power structure of it. They also have the opportunity to continuously observe the consultee and clients to which they provide services. The disadvantages arise when there are power plays involved, or poor relations within the system (Jaffe, 1992b). However, the consultation process works similarly regardless of whether the consultant is internal or external or is doing individual or group consultation (Kurpius, Fuqua, \& Rozecki, 1993).

\section{Consultation as an Alternative to Direct Service}

Due to a projected increase in the school population of children with disabilities and a shortage of OTs, there may need to be an increase in the number of students served through consultation and a decrease in the number of students receiving direct service. In a school setting, priority for service is to enhance education and a lesser priority is medical treatment. Therefore, consultation should 
be considered an alternative for service if the goals for the student can be achieved (Gilfoyle \& Hays, 1979).

In their survey of OTs and administrators, Gilfoyle and Hays (1979) found that both felt therapists need additional training in consultation and in effective consultation processes within educational programs, and in understanding of educational priorities, theories, and delivery systems.

\section{Training/ Preparedness for Consultation}

Should selection of consultant candidates be restricted to persons who already possess expertise in their field and communicative/interactive skills? Is training in the area of consultation necessary to be effective? Idol and West (1987) looked at whether or not consulting skills can be taught and the effectiveness of several existing special education training programs. They found that indeed consultation skills can be taught using a systematic approach (Lilly, 1979) .

In a survey of state departments of education, West and Brown (1987) reported that although 26 states include consultation in their service delivery options, only 13 have delineated specific roles and responsibilities within the job descriptions of those special educators expected to fulfill a consultative role. Only seven had specific consultation competency requirements in their policies, rules, or guidelines. Idol and West (1987) critiqued six special 
education service delivery options involving consultation. What they found suggests that the majority of consultation service delivery options used an effective teaching/content skills knowledge base for problem solving with little emphasis on the communicative/ interactive skills upon which states' policies place so much emphasis. They suggested further research to determine the relative importance of communicative/interactive skills and effective teaching/content skills in successful consultation.

Since many OTs who provide consultative services are employed under the same policies as special education departments, it should be examined whether or not they are being trained to provide these services within the school system. Training is recommended for all OTs who provide consultative services by either formal means or on-the-job training. However, consultation is frequently seen as a potential area of practice without providing the detailed training in the specific skills required for a successful consultant. More health professional schools should acknowledge consultation as a vital and growing area for the practice of their profession and include these basic concepts, processes, and procedures in the curriculum (Jaffe \& Epstein, 1992b). Training can also be gained through workshops or continuing education classes or by on-the-job training by peers or superiors. Recognition has been given to the importance of systematic training and course work in consultation as consultative activities have increased (Medway, 
1982) and consultation skills have been recommended for inclusion in graduate training programs of a number of professional specialties (Zaffrann, 1979).

There has been some controversy on whether there should be an emphasis on theory or process and skills and use of structured or unstructured teaching methods (Alpert, Silverstein, \& Haynes, 1980). Many graduate programs in several psychological specialties are now offering coursework preparation in consultation (Randolph \& Magee, 1984). Randolph and Magee (1984) developed two paper and pencil instruments to measure consultation skills. One measures recognition of critical elements in a consultation situation and the second goes one step further and also measures the ability to make a clinical judgment as to what action should be taken by the consultant. The authors have reportedly been working to validate these instruments.

Cary Cherniss (1978) stated that the relationship between consultant and consultee was integral to the success of the consultation process, and that consultees differed in their readiness to receive consultation services. He stated that most professionals do not receive formal training in consultation techniques which has interfered with effective, widespread use of consultation in human service programs. He developed the Consultation Readiness Scale to fill the need for a concrete instrument that would permit the assessment of a consultee's readiness level. 
Alderton (1983) presented a course model to improve the professionalism of persons who wish to engage in consultation and stated that consultation without a clear focus or conceptual posture will probably lead to random and ineffective helping efforts. The course has two units: students identify biases about the process and determine how they might realistically and ethically intervene, and the process phase which calls for an isolation of skill necessary for performing various roles.

A study done by Bergan and Tombari (1976) which observed a relationship between consultant skills and efficiency and problem identification, as well as the power of consultation to solve educational problems, suggested the importance of intensive instruction in consultation in graduate training programs. Because the prerequisites for consultation competency have recently been shifted from personality characteristics and traits to skills and techniques, Bushe and Gibbs (1990) conducted a survey of behaviors indicative of change-oriented consulting practice. The survey addressed whether specific character traits of consultants were more likely to lead them to use those behaviors effectively in consultation. They found that they were, but recommended further research since these measures of success are open to various distortions having little to do with the consultant's competence.

The guidelines for occupational therapy services in school systems, published by the American Occupational Therapy 
Association, lists fifteen statements regarding specialized competencies necessary to function in the school system (Chandler, Dunn, \& Rourk, 1989). In the last decade there has been an increasing trend to train OTs in consultation and monitoring in addition to the direct service model. This occurred in response to the need to provide a wider breadth of services in the school system since there has been an increasing pressure to assume consultative and monitoring roles with a corresponding decrease in direct service roles (Royeen \& Coutinho, 1991)

\section{Relationship Between OTs and School Personnel}

A large predictor of success for occupational therapists as consultants is their level of relationship with school personnel, particularly those receiving the consultative services. PL 94-142 has focused national attention on the importance of working partnerships and teamwork to the delivery of optimally effective services to children with disabilities (McCormick \& Lee, 1979). However, the underlying issue of philosophical integration required as professionals from various disciplines unite to provide services for the disabled populations has not been directly addressed (Ottenbacher, 1982).

Goals, roles, expectations. Occupational therapists working in the schools are faced with finding ways to define and engage in their practice through models compatible with education, medicine, and 
rehabilitation. Thus, "the OT must understand and be fluent in a number of perspectives applicable to service provision in the public schools and have the ability to blend those perspectives while maintaining a clear OT identity" (Colman, 1988, p. 705). Occupational therapist and speech language pathologist respondents to a survey done by Edwards and Hanley (1992), reported many perceived benefits to interdisciplinary activity within the schools. The OTs also reported some uncertainty about their role. The authors believe this uncertainty indicated a need may exist for institutions of higher education to establish a comprehensive interdisciplinary professional education to improve the quality and efficiency of service delivery to children.

Philosophy/ conceptual models. Hanline (1990) found that in implementing a new teacher consulting model, the ability of the integration specialist to collaborate with other professionals was a key factor contributing to successful outcomes. The ultimate effectiveness of the mandated multidisciplinary service approach will depend on therapists and educators developing an understanding and appreciation of various practice and treatment models. Both disciplines are struggling to establish independent conceptual bases, with OT being theoretically grounded in medical model logic and educators trying to disassociate themselves from this model to a task analysis model (Jaffe \& Epstein, 1992a). The two models must be used in combination in order to achieve total education and 
habilitation, and therapists are in a position to facilitate the synergistic development of the two models because they have exposure to both (Ottenbacher, 1982). Possible sources of conflict in school situations is when classroom teachers question the efficacy of what's being done with a student while missing general class time, when goals of teachers and other professionals are mutually exclusive, and when professionals are competing for time with the same students. Goals, roles, expectations, and what the team will work on together should be established up front (Idol and Baran, 1992). The consultation process addresses all of these issues.

Edwards and Hanley (1992) found that perceived barriers to interdisciplinary activity include staff shortage, financial constraints, physical barriers, lack of support, conflicts regarding procedures to accomplish goals, and philosophical conflicts. These findings suggest that academic institutions that train professionals should explore models for cooperative planning and development of common diagnostic and/or training goals and activities to be pursued. Some professional training programs have played down and in some cases, even disparaged the contributions of other disciplines. Because of this, students are insulated from exposure to the tenets of other disciplines and learn to be suspicious of other professionals and protective of philosophical biases and unique competencies of their own disciplines (McCormick and Lee, 1979). 
These differences separate the disciplines and hamper the interdisciplinary process. OTs in the schools must clarify their roles in this setting by using terminology that others can understand since communication is affected negatively by the use of jargon (Dustin \& Ehly, 1992), clarify and increase the marketability of school-based OT by defining a conceptual framework, delineate between the role of OT and other related services, and implement strategies to further secure the position of OT in their schools (Royeen \& Marsh, 1988).

OT role. Fairbairn and Davidson (1993) surveyed teachers' perceptions of OTs in the school and had four major findings: all teachers valued the work of OTs in schools, teachers expressed confusion over the roles of OTs, teachers disagreed with OTs about some of their roles, and teachers believed OTs needed to develop a better awareness of the needs of the education system. Those teachers also perceived that OTs should continue to spend most of their time in classroom consultation, but spend significantly more time in class consultation, program implementation, and planning rather than in assessment and documentation.

OT in the educator's classroom. Therapists entering the school system become a part of that system and need to understand it as a whole in order to perceive their own role more clearly (Regan, 1982). The relationship of OTs and school personnel can be enhanced by use of the collaborative consultation model. It focuses 
on the ongoing communication among team members and joint problem solving within the team, acknowledging the unique contributions and shared responsibilities of each discipline. In addition conflict resolution occurs based on mutual commitment to a common goal, and effective communication strategies are applied by all members (Dunn, 1992).

Chandy (cited in West \& Idol, 1987) found that teachers who received inservice training used consultative services more often, initiated more consultative contacts and discussed student academic and behavioral problems more often than those who did not.

Whitworth (1994) supports increased understanding among school personnel to allow many activities to be incorporated within the classroom, and consultation and increased education and training of teachers/aides to carry out programs set up by OTs to increase support and enhance the work of OTs and increase consistency for each child served. When an OT enters the school system, her ability to define her role within the educational context, establish relationships, and market herself as someone who is going to help the teacher and make her job easier through consultative services may make or break the success of her role in that setting.

There are many ways an OT can aid teachers in serving a disabled child in the classroom. By addressing the child's opportunity to respond and achieve, the proportional interaction 
between teachers and students, and acceptable social relationships between disabled and exceptional students, the OT consultant is able to focus on preventive measures the regular teacher can use to reduce possible classroom management problems as well as enhance the learning atmosphere (Heron \& Harris, 1987). This collaboration can help prepare teachers and increase success of the integration process (Heron \& Harris, 1987). 


\section{Chapter 3}

\section{Research Methodology}

\section{Research Questions}

1. Do occupational therapists believe they possess the competencies needed to provide collaborative consultative services within the schools?

2. With whom do occupational therapists engage in school consultations, how often, and how do they view these relationships?

3. How much training and/or education have occupational therapists received on how to be an effective consultant?

4. What are the perceived barriers and perceived benefits to the consultative process within the school system?

5. How do experience, training, age, and highest degree relate to self-perceived consultant skills in occupational therapists?

\section{Participants}

Occupational therapists who are members of the Florida Occupational Therapy Association and employed by the public school system were chosen to participate in this study. The inclusion criteria for participants were that they must be registered occupational therapists providing consultative services in the school system and reside within the state of Florida. The listing of names was provided by the Florida Occupational Therapy Association 
so all participants are members of that organization. Direct contact was made with this organization by the researcher and the list was supplied using the members who subscribe to the Special Interest Section on Schools. There were 150 names on the list and five names were eliminated based on personal knowledge that those persons were not practicing or otherwise did not meet the inclusion criteria. A final sample of 145 participants were surveyed.

\section{Procedures}

The present study was developed to obtain information from the participants regarding their attitudes, roles, and perceived skills as consultants.

All subjects were sent a copy of the survey along with a cover letter explaining the purpose of the study via U.S. mail (See Appendix A). A self-addressed stamped envelope was also provided for return to the primary investigator. To increase the response rate, a follow-up postcard was sent to respondents one month after the initial mailing to encourage a response from those who had not already done so. Each survey was coded by the principal investigator to identify participants who needed to receive a follow-up postcard.

The questions contained in the survey were based on the assumption that the respondents were providing consultative services as an indirect service model within the school system. A 
definition of collaborative consultation was included in the cover letter (See Appendix B).

Instrument

At the present time no standardized instrument exists to assess the preparation of occupational therapists to act as consultants. As a result, a questionnaire of 32 multiple choice and checklist format questions was developed based on literature, the competencies listed in AOTA's guidelines (Chandler, Dunn, \& Rourk, 1989), and the nature of the research questions. While reviewing the literature, areas to be investigated were identified and research questions were developed. Once the research questions were identified the survey questions were developed and put into categories. The categories include demographics, time spent in consultation and with whom, type of consultation model used, relationships with teachers, perceived benefits/barriers to the consultative process, and perceived preparedness/training/skills for providing consultation. Each category was designed to target a specific research question. The author was guided by mental health and organizational development literature which was then applied to the occupational therapy profession.

Demographics. The first set of questions were designed to obtain demographic information with questions about the name of the school system, age, sex, years employed in the profession, the 
schools, and their present setting, educational level, and any special certifications held.

Time spent In consultation/type of model used. Research question \#2, with whom do occupational therapists engage in school consultations, how often, and how do they view these relationships, was addressed with questions \#3 through \#14 regarding the actual and preferred amount of time spent in consultation. Respondents were asked to indicate the model of consultation they use most often, which model they prefer to use, with whom consulting is done and how often, the amount of time actually spent in consultation, and the amount of time they would prefer to spend in consultation. A multiple choice format with closed-ended questions was used for these questions and the choices were obtained from the literature (Costenbader, Swartz, \& Petrix, 1992) along with suggestions from therapists currently employed in the school system who participated in the pilot study.

Relationships with teachers. To further address research question \#2, survey items \#15,16, 17 asked respondents to rate their relationships with teachers with whom they provide consultative services. Item \#16, regarding the relationship between the consultant and consultee as a predictor of consultee's readiness for the consultation process, was taken from Cherniss' Consultation Readiness Scale (Cherniss, 1978). 
Perceived barriers/benefits to the consultative process. To address research question \#4, what are the perceived barriers and perceived benefits to the consultative process, items \#18, 19, 20 were formulated. Respondents were asked to "check off" on a check list the roles they assume when consulting, perceived benefits of collaborative consultation, and to what extent they found a list of items to be barriers to the consultation process using a three point scale. These questions were developed using literature on roles (Epstein, 1992; Heron \& Harris, 1987), benefits (Edwards \& Hanley, 1992) and a previous study done on the interdisciplinary activity between occupational therapists and speech language pathologists (Edwards \& Hanley, 1992). Suggestions from occupational therapists participating in the pilot study regarding validity, language, and answer choices were also used to address this question. A multiple choice item (\#21) was also included in this section asking what the therapists' motivators were for engaging in collaborative consultation and which type of services they believed were most needed to meet individual student needs.

\section{Perceived preparedness/training/skills for providing}

consultation. To address research question \#3, how much training and/or education have OTs received on how to be effective consultants, the fifth set of items, \#22 through \#29, concerned the amount of consultative training the respondents had received. Multiple choice items asked respondents to indicate the amount of 
formal and informal training they had received, through what means, to rate the training, and how important they believed training is to function as an effective consultant.

To address research question \#1, do OTs believe they possess the competencies needed to provide consultative services within the schools, the final item (\#30) addressed the respondents' perceived skills in a number of areas imperative to the consultative process. Ten abilities or skills were listed and respondents were asked to rate themselves using a Likert response format with values from $1=$ "inadequate" to $5=$ "superior ability". This list was developed using the literature on what competencies are necessary for providing consultation services (Bergan \& Tombari, 1976; Chandler, Dunn, \& Rourk, 1989; Costenbader, Swartz, \& Petrix, 1992; Hamilton, 1988; Idol \& West, 1987; Knoff, et al, 1991). The final question asked the respondents if they believed collaborative consultation was an effective treatment method for the school setting and if they will use it in the future.

Research question \#5, how do experience, training, age, and highest degree relate to self-perceived consultant skills, is addressed by correlating demographics with item \#30.

The Pilot Study. A pilot study was conducted using five therapists who were currently providing consultative services within the school system. The subjects were obtained through a graduate course at a major university in a large metropolitan city in 
south Florida. The purpose of this was to examine the face validity of the questionnaire, to determine whether the questions were clearly stated and unambiguous, and to receive feedback and suggestions on the questions prior to its distribution. This feedback was utilized in revising the questions, determining amount of time needed for completion, and assessing proper interpretation of content.

\section{Statistical Analyses}

The data was analyzed using a Statistical Analysis Program (SAS, 1985) run on the University mainframe. Measures of central tendency including frequencies, percentages, and means were conducted on each question. Pearson $r$ correlations were used to compare age, special certifications held, and amount of experience and training with perceived skills.

Crosstabulations using Fisher's exact test were conducted to compare the primary model of consultation used with reported relationships with teachers.

A one-way analysis of variance (ANOVA) was conducted to compare the mean of the overall self-perceived skills with amount of informal/formal training received. This analysis was conducted to investigate if any relationship existed between the amount of training and self-perceived skills. 
Limitations

The major limitation of this study is that the information obtained was based on self-perceptions. As a result, the answers may be biased by respondents answering questions according to the way they think a question should be answered, or based on some other professional expectation. Also, there is no way to ensure the respondents interpreted the questions the way they were intended, or that the answers were examined as they were intended. This possible source of error was minimized through the pilot study and subsequent revisions, but the potential for bias still remained.

The survey was mailed out to 145 subjects, with 46 of the 80 questionnaires returned being usable. This is a response rate of $31.7 \%$. Another limitation of the study is that the subjects are only those therapists who are members of the Florida Occupational Therapy Association. It is presumed that this sample is representative of the population of therapists in Florida. One possible explanation for the small sample size is that the study was conducted during the summer months, during which many school personnel take vacation. 


\section{Chapter 4}

$\underline{\text { Results }}$

One hundred forty-five occupational therapists were sent a copy of the questionnaire with 80 being returned to the principal investigator. Of these 80,46 , or $31.7 \%$ of the total mailout, met criteria for inclusion. The other 33 respondents, or $22.7 \%$, who did not meet the criteria for inclusion, were not currently working in schools or did not provide consultative services as described in this study.

\section{Demographic Results}

The age range of the respondents was 26 to 57 years with a mean age of 40.7 years. The majority of respondents reported working full time, though a few work part time or as consultants only. Female respondents greatly outnumbered male respondents and the respondents were from various counties throughout Florida. These counties included: Broward, Palm Beach, Dade, Pinellas, Pasco, Manatee, Lee, Brevard, Sumter, Santa Rosa, Nassau, Hillsborough, Walton, and Orange Counties (See table 1).

The range for years employed in the profession was 1 year to 35 years with a mean of 13.8 years. Years employed in the schools ranged from 1 to 26 years with a mean of 7.8 years. Years employed 
in their present setting ranged from less than one year to 24 years with a mean of 5.5 years (See table 2).

The highest degree held by respondents varied from bachelor's degree to master's degree with one respondent reporting currently working as a COTA while completing her bachelor's degree. Eightythree percent held highest degree in occupational therapy. Other areas in which highest degrees were held include: counseling, nursing, special education, and elementary education. Special certifications held include neurodevelopmental treatment certification, sensory integration certification, and pediatric certification.

Amount of Time Spent/Preferred in Consultation

The range of scores for amount of time spent in consultative services was from 3 to 5 times a week to once a month. However, the majority of respondents provided consultative services 3 to 5 times a week. (See table 3)

The reported ideal amount of time spent in consultation ranged from twice a day to once a month. However, the majority of respondents believed it should be determined as needed per child.

\section{Recipients of Consultation Services}

Ninety-one percent of respondents reported that interdisciplinary planning and interaction occur on a consultation 
basis. When asked with whom they consulted, respondents reported regular classroom teachers, special education teachers, family members, physical therapists, speech/language therapists, other occupational therapists, and outside agencies. (See table 4)

\section{Service Delivery Options}

Most respondents provided direct service as well as consultative services $(88.6 \%)$. The majority believed both direct service and collaborative consultation best meet student needs $(69.2 \%)$ rather than either service model alone.

Approximately $57 \%$ of respondents used a standardized evaluation to determine who received consultative services, and $57 \%$ believed one should be used.

Model of Consultation Used/Preferred

The primary model of consultation used by respondents was collaborative, though $11 \%$ reported using no particular model. When asked what type of model they preferred to use, most preferred the collaborative consultation model. (See table 5)

\section{Perceived Relationships With Educators}

The majority of participants $(54.5 \%)$ did not believe the educational staff at their schools understand the role of OTs in 
school settings. However, most respondents rated their relationships with educational staff as good or fair. (See table 6)

Participants were asked to rate the level of relationship between themselves and the teachers with whom they consulted. The levels of relationship ranged from no relationship to reciprocal work relationship. These levels are described as: no relationship in which the consultee is hostile, indifferent, or apathetic; social relationship in which there is informal, social contact only; limited work relationship in which the consultee asks for help but does not follow through; adequate work relationship in which the consultee is open to the consultant, and initiates contact; informed work relationship in which the consultee initiates contact and effectively participates in the process; and reciprocal work relationship in which the consultee seeks consultation and is an active advocate for consultation. Participants were asked to choose only one level, and the majority chose adequate work relationship, informed work relationship, or reciprocal work relationship. Many respondents commented that the level of relationship varied from teacher to teacher.

\section{Perceived Barriers to the Consultation Process}

Participants were asked the degree to which they found certain items to be barriers to the consultative process. Those barriers reported most often were inadequate time, staff shortage, 
lack of intervention follow-through, financial constraints, and physical barriers (Edwards \& Hanley, 1992). (See table 7)

\section{Perceived Benefits of the Consultation Process}

Participants were also asked what they found to be benefits of collaborative consultation. The benefits reported most often were opportunity for critical exchange of information, more followthrough of teachers, improved quality of treatment, and efficiency of treatment. (See table 8)

Roles Assumed While Consulting

Respondents were asked what roles they assumed when consulting using a list provided on the questionnaire. The roles chosen most often were joint problem solver, professional, information specialist, and indirect service provider. (See table 9)

Motivators for Engaging in Consultation

When asked what their motivators were for engaging in consultation, most responded requests of teachers, self-motivation, or that they believed children need less treatment time than direct service provides. One person commented that she is motivated to consult because children need more time than direct service provides. (See table 10) 


\section{Training Variables}

The amount of formal training received by respondents ranged from none, to more than one year. Approximately $61.5 \%$ of respondents reported receiving formal training on how to be an effective consultant. This training was received through various means, from undergraduate curriculum, on-the-job training, to selfstudy courses. (See table 11)

The amount of informal training received ranged from one hour to one week, though $34.2 \%$ of respondents reported that informal training occurred on an ongoing basis.

The quality of training received was rated mostly as adequate or more than adequate, though a few respondents rated their training as less than adequate. When asked how important training is to function as a consultant, the majority reported it to be only mildly important. None of the respondents reported that training was not at all important for the consultative process.

Perceived Importance of Background/Knowledge in Competency $\underline{\text { Areas }}$

Participants were asked how important they believed background or knowledge in various areas were for consultation. These factors were taken from the literature on competencies needed to provide consultative services. Many respondents reported that knowledge of occupational therapy, understanding of 
professional ethics, and education and training in human development were very important to perform consultation. (See table 12)

Self-Perceived Consultation Skills

Participants were asked to rate their skills in ten areas assumed to be necessary competencies for a good consultant (Jaffe \& Epstein 1992b, West \& Idol, 1993). The majority of respondents rated themselves as adequate or more than adequate, with the overall mean of all skills listed falling in that range (3.62). (See table 13)

Correlations Between Use of Service Models and Perceived Relationships with Educators

Crosstabulations were performed to investigate whether a relationship exists between the primary model of consultation used and relationships with teachers. (See table 14) Fisher's exact test revealed no significant relationship.

However, the following percentages were found: $40.0 \%$ of the $46.0 \%$ who believed the educational staff understands the role of OT, used the collaborative consultation model. Approximately $52.0 \%$ of the $73.5 \%$ of respondents who reported a good relationship with teachers, used the collaborative consultation model. Approximately 
$66.7 \%$ out of the $27.0 \%$ who reported having a reciprocal relationship with the teachers they consult with, used the collaborative model.

A significant relationship was found between how respondents rate their relationships with teachers and the level of relationship they reported having with teachers $(p<.05)$. Of the $75.8 \%$ who answered that they have a good relationship with teachers, $35.0 \%$ of that sample reported having a reciprocal work relationship.

\section{Correlations Between Demographics and Training}

Pearson correlations revealed no significant relationships between the demographics (age, sex, special certifications, years employed in the profession, present setting, or schools) and selfrating of consultant skills. (See table 15)

A one way analysis of variance was conducted to determine whether any significant differences existed between the mean selfrating of consultant skills and the amount of training received. The mean of all self-perceived skills with self-study as the type of formal training received was found to be significant $(p<.01)$. The respondents who reported self-study as one of their means of training rated themselves as more than adequate in consultant skills.

One other area that approached significance was the relationship between how important respondents believed formal training is with the overall mean of self-rated skills. Those persons 
that rated their skills as between more than adequate and superior feel formal training is mildly important.

One hundred percent of respondents answered that they believed collaborative consultation is an effective treatment method for the school setting and all but one respondent $(97.7 \%)$ said that they would use it in the future. 


\section{Chapter 5}

\section{Discussion}

While the need for occupational therapists (OTs) to provide services within the schools continues to rise, little research has been done on OTs as consultants in the schools. Particularly, few studies have focused on the readiness for the consultation process or attempted to clarify what role this readiness plays on the success of consultation (Dunn, 1988). This study investigated whether OTs are currently performing the role of consultant, have been trained to perform this role, their attitude toward the role, and how they perceive their own skills in this area.

From the current study it was found that many OTs are indeed providing consultative services within the schools and most OTs rate their basic consultation abilities as more than adequate. Interestingly, while $61.5 \%$ reported having received formal training, $73.7 \%$ of those felt only adequately prepared to provide consultative services. The majority of respondents reported receiving less than one semester of formal training and that their informal on the job training occurred on an ongoing basis. The majority of respondents rated their training as adequate and felt that training was only mildly important. This would seem to indicate that OTs have received less than adequate formal training but don't believe formal training is very important. Also significant is the finding that zero 
respondents reported that training was not important. A significant relationship was found between those rating their skills as more than adequate and choosing self-study as the type of training received.

These findings have interesting implications for this study. OTs may believe their consultation skills are adequate in spite of an overall lack of preparation to act as consultants. Also, perhaps because the quality of training received is seen only as adequate by many of the respondents, they do not place much merit in formal training methods. The significant relationship found between respondents reporting self-study as one of their means of training and rating of skills as more than adequate would indicate that perhaps therapists feel their quality of training was merely adequate and that self-study is the best means of developing consultative skills. However, it points out that most OTs who are providing consultative services within the schools have not been formally trained prior to undertaking this role. The results of this study uphold the findings of previous studies (West \& Brown, 1987; Idol \& West,1987) that most educational personnel, including therapists employed by schools, do not receive training on how to be an effective consultant.

According to the results of this survey, occupational therapists spend most of their time consulting with special education teachers. They spend on the average between one hour and 
five hours per month in consultaton with special education teachers as well as other professionals. The discrepancies between actual and preferred amount of time spent in consultation supports Costenbader, Swartz, and Petrix's (1992) findings that actual and preferred amount of times spent in consultation vary and that amount of time spent does not relate to demographic variables, training variables, or perception of consultative skill. It may be that actual time spent in consultation is related to perceived barriers to the consultation process. For example, inadequate time for consultation, lack of follow-through by consultees, financial constraints, and physical barriers are all seen as barriers to the consultation process by respondents and may contribute to the discrepancy between the actual amount of time spent in consultation ( 3 to 5 times per week) and the ideal amount of time indicated by most respondents (as needed per child) to be spent in consultation. Overall, OTs rated their relationships with teachers as good or fair. The level at which they rated the work relationship varied, and respondents indicated that it often varies with the teacher. Several respondents commented that special education teachers were more receptive to OT intervention than regular education teachers. It is interesting to note that of the $73.5 \%$ who reported having a good relationship with teachers, $52.0 \%$ use the collaborative model and $66.0 \%$ of those who reported having a reciprocal relationship with teachers use the collaborative model. This provides evidence in 
keeping with Dunn's (1992) and Chandy's (1987) findings that the relationship of OTs and school personnel can be enhanced by use of the collaborative consultation model and treatment approach. The collaborative consultation model places emphasis on the interactive process, mutuality, and reciprocity which leads to shared responsibilities, partnership, and a positive growth experience for both parties involved (Idol \& West, 1987). Overwhelmingly, the respondents reported liking the collaborative consultation model and believe that collaborative consultation is an effective treatment method for the schools. They do, however, feel that direct service and collaborative consultation together best meet student needs.

Respondents of this survey reported that there are many benefits to collaborative consultation. These benefits include improved quality of treatment, efficiency of treatment, the opportunity for critical exchange of information, and more follow through of teachers. This would indicate that collaborative consultation is indeed an effective treatment model that improves quality of treatment for children with disabilities as well as enhances relationships with teachers.

Occupational therapists reported several barriers to the consultative process. These include inadequate time for consultation, lack of intervention follow through by consultees, staff shortages, financial constraints, physical barriers, and lack of support and cooperation by teachers. These are issues that need to 
be addressed by educational personnel and administration as well as the occupational therapists providing consultative services, to alleviate barriers and improve the consultative process. It would be interesting to investigate this issue from the educational staff's perspective as well to see where they stand on the issue and if they see similar barriers to the consultation process.

From the results of the present study, there seems to be no significant relationship between age or amount of experience and level of perceived consultant skills. This leads one to believe that OTs providing consultative services feel comfortable with their skill level regardless of amount of time at their present setting or in the profession. This is in accordance with the findings that most training occurs "on the job" on an ongoing basis. In addition to the concern that OTs may be learning how to be a consultant through trial and error means, there is the concern that many OTs providing consultant services within the schools may rate themselves higher in skills than they actually should due to lack of formal training on what actually does comprise a skillful consultant.

Another interesting finding in the study is the fact that the majority of respondents have their highest degree in occupational therapy $(83.7 \%)$ and a small number have received master's degrees $(27.9 \%)$. This would indicate that many OTs providing consultative services in the schools have not sought out further education beyond their bachelor's degree in OT. 
The majority of the respondents have been working in the schools for less than 12 years, with almost one third working 4 years or less. Interestingly, the majority of respondents have been working in their present setting 3 years or less. This limited time in present setting may be affecting the attitudes and trends of the respondents regarding their relationships with educators and their views on the consultation process.

Consultants are viewed as having expertise far beyond that of entry-level personnel. While the level of expertise will vary between individuals, the client or consultee expects the consultant to have acquired requisite knowledge and skills and to have maintained this competence through ongoing study (Jaffe \& Epstein, 1992d). From the results of this study, it is not certain that all OTs providing consultative services in the school setting are striving to maintain this competence through any means of ongoing study.

This study touches on several issues that have implications for OT practice. Consultation is a service model that is being implemented often in the educational setting (Jaffe \& Epstein, 1992a). As indicated in this study, many OTs are currently using it in their treatment of students with disabilities in the public schools. OTs do not appear, however, to receive any type of formal training on how the consultation process works or what makes an effective consultant. While OTs perceive their overall consultant skills to be more than adequate, is it ethical to treat clients in a 
manner in which we have not been formally trained? These findings would indicate that more education on consultation should be included in the undergraduate OT curriculum, and available through other means such as workshops, inservice training, or self-study courses.

\section{Recommendations for Future Research}

Further research is recommended to assess how many OT programs include consultation as part of their basic undergraduate or graduate curricula or how often workshops and continuing education courses on consultation are offered. Also, to validate the findings of this study, it is recommended that a similar study be done addressing the other portion of the consultative triad, the consultee or teacher receiving consultative services from OTs. A look at their attitudes and perceptions regarding the consultative process and relationships with therapists would provide valuable insight on how to improve these relationships. Another interesting angle to investigate would be an objective study of OTs in the schools and their behavior in the consultation process. This may provide insight into what services OTs are actually providing during consultation and how comfortable/competent they seem in this role.

A similar study could also be conducted with physical therapists providing consultative services to teachers in the 
schools. A comparison could be drawn between the two disciplines and investigate where common problems may lie.

An interesting finding was that 34 OTs returned the questionnaire unanswered due to no longer providing services within the schools or as defined in this study. This was disappointing but raises the question of the nature of OTs in pediatric service or in the schools, and why so many were no longer providing services in this manner. This may be an example of the high turnover in the OT profession, though a repeat study or expansion to the national level might provide more insight into this matter.

Because all qualified participants who returned the questionnaire are currently providing consultative services within the schools, their perceptions regarding consultation as a service model or their own consultative skills may be biased. The findings of this study could be further validated by doing a repeat study or expanding the study to a national level.

\section{Summary}

The findings of this study indicate that the majority of OTs providing collaborative consultation in the school system have received very little formal training in this area. These OTs view training in consultation as important but only mildly so. These therapists also rate their skills in consultation competency areas as adequate or slightly more than adequate. This raises the question of 
how OTs are measuring or evaluating the effectiveness of their consultative efforts.

The findings also indicate that age, amount of experience, training, and highest degree held do not make a difference in selfperceived consultant skills.

All of the respondents reported finding benefit in the use of collaborative consultation in the schools and found several key factors to be barriers to the process. These barriers, inadequate time, physical barriers, lack of follow-through, and staff shortage are issues that can be addressed by all members of the interdisciplinary team.

Overall therapists consulting in the schools rate their relationships with teachers as good or fair but do not believe they understand the role of OT in the school setting. This may be due to a difference in philosophical bases (Ottenbacher, 1982), and is an important finding since it is the OTs' responsibility to educate other professionals regarding their role. Without such an effort to educate them, differences in philosophical bases may limit understanding of the OT role.

The findings from this study indicate that more training in consultation needs to be made available to OTs practicing in the schools, more attempts must be made to educate other professionals about consultation and the OT role, and some of the barriers to the process must be eliminated for the service model to be a success. 
References

Alderton, S. (1983). Survey course in organizational communication consulting: A processual model. Communication Education, 32, 413-420.

Alpert, J., Silverstein, J., \& Haynes, R. (1980). Utilization of groups in training for consultation. Journal of School Psychology, 18, 240246.

Alpert, J. \& Yammer, M. (1983). Research in school consultation: A content analysis of selected journals. Professional Psychology: Research and Practice, 14, 604-612.

Bergan, J. \& Tombari, M. (1976). Consultant skill and efficiency and the implementation and outcomes of consultation. Journal of School Psychology, 14, 3-13.

Bushe, G. \& Gibbs, B. (1990). Predicting organizational development consulting competence from the Myers-Briggs Type Indicator and Stage of Ego Development. The Journal of Applied Behavioral Science, 26, 337-357.

Chandler, B., Dunn, W., \& Rourk, J. (1989). Guidelines for Occupational Therapy Services in School Systems, 2nd ed. Rockville, MD: The American Occupational Therapy Association.

Cherniss, C. (1978). The consultation readiness scale: An attempt to improve consultation practice. American Journal of Community Psychology, 6, 15-21. 
Collier, T. (1991). The screening process. In W. Dunn (Ed.). Pediatric Occupational Therapy: Facilitating Effective Service Provision (pp. 11-33). New Jersey: Slack, Inc.

Colman, W. (1988). The evolution of occupational therapy in the public schools: The laws mandating practice. The American Journal of Occupational Therapy, 42, 701-705.

Cook, D.G. (1991). The assessment process. In W. Dunn (Ed.). Pediatric Occupational Therapy: Facilitating Effective Service Provision (pp. 35-72). New Jersey: Slack, Inc.

Costenbader, V. Swartz, J. \& Petrix, L. (1992). Consultation in the schools: the relationship between preservice training, perception of consultative skills, and actual time spent in consultation. School Psychology Review, 21, 95-107.

Coutinho, M. J. \& Hunter, D. (1988). Special education and occupational therapy: Making the relationship work, American Journal of Occupational Therapy, 42, 706-711.

Dunn, W. (1989). Integrated related services for preschoolers with neurological impairments: issues and strategies. Remedial and Special Education, 10, 31-39.

Dunn, W. (1988). Models of occupational therapy service provision in the school system. American Journal of Occupational Therapy, 42, 718-723. 
Dunn W. (1990). A comparison of service provision models in school-based occupational therapy services: A pilot study. The Occupational Therapy Journal of Research, 10, 300-319

Dunn, W. (1992). Occupational Therapy Collaborative Consultation in Schools. In E. Jaffe \& C. Epstein (Eds.). Occupational Therapy Consultation: Theory, Principles, and Practice (pp.210-236). St. Louis: Mosby-Year Book, Inc.

Dunn,W. \& Campbell, P. (1991). Designing pediatric service provision. In W. Dunn (Ed.). Pediatric Occupational Therapy: Facilitating Effective Service Provision (pp. 139-159). New Jersey: Slack, Inc.

Dustin, D. \& Ehly, S. (1992). School consultation in the 1990's. Elementary School Guidance and Counseling, 26, 165-175.

Edwards, S. \& Hanley, J. (1992). Survey of interdisciplinary activity between occupational therapists and speech language pathologists in the public schools. The Occupational Therapy Journal of Research, $12,35-49$.

Epstein, C. F. (1992). Consultation: Communicating and facilitating. In J. Bair \& M. Gray (Eds.), The Occupational Therapy Manager (pp.291312). Rockville, MD: The American Occupational Therapy Association, Inc.

Fairbairn, M. \& Davidson, I. (1993). Teachers' perceptions of the role and effectiveness of occupational therapists in schools. Canadian Journal of Occupational Therapy, 60, 185-191. 
Gilfoyle, E. (1992). Future Directions: Vital Connections. In E. Jaffe \& C. Epstein (Eds.). Occupational Therapy Consultation: Theory. Principles, and Practice (pp. 777-783). St. Louis: Mosby-Year Book, Inc.

Gilfoyle, E. \& Hays, C. (1979). Occupational therapy roles and functions in the education of the school-based handicapped student. American Journal of Occupational Therapy, 33, 565-576.

Hamilton, E. (1988). The facilitation of organizational change: An empirical study of factors predicting change agents' effectiveness. The Journal of Applied Behavioral Sciences, 24, 37-57.

Hanline, M. F. (1990). A consulting model for providing integration opportunities for preschool children with disabilities. Journal of Early Intervention, 14, 360-366.

Heron, T. E. \& Harris, K. C. (1987). The Educational Consultant, (2nd ed.). Austin, Texas: Pro-Ed Publishing.

Hopkins, Helen L. (1988). An introduction to occupational therapy. In H. Hopkins \& H. Smith (Eds.). Willard and Spackman's Occupational Therapy (p.3). Philadelphia: J. B. Lippincott Co.

Idol, L. \& Baran, S. (1992). Elementary school counselors and special educators consulting together: Perilous pitfalls or opportunities to collaborate? Elementary School Guidance and Counseling, 26, 202212.

Idol, L. \& West, F. (1987). Consultation in special education (part II): training and practice. Journal of Learning Disabilities, 20, 474-494. 
Jaffe, E. (1992a). Theoretical concepts of consultation. In E. Jaffe \& C. Epstein (Eds.). Occupational Therapy Consultation: Theory, Principles, and Practice (pp.15-54). St. Louis: Mosby-Year Book, Inc.

Jaffe, E. (1992b). Approaches to consultation. In E. Jaffe \& C. Epstein (Eds.). Occupational Therapy Consultation: Theory, Principles, and Practice (pp. 86-117). St. Louis: Mosby-Year Book, Inc.

Jaffe, E. \& Epstein, C. (1992a). The history of professional consultation: an overview. In E. Jaffe \& C. Epstein (Eds.). Occupational Therapy Consultation: Theory. Principles, and Practice (pp. 3-14). St. Louis: Mosby-Year Book, Inc.

Jaffe, E. \& Epstein, C. (1992b). Preparaton for consultation. In E. Jaffe \& C. Epstein (Eds.). Occupational Therapy Consultation: Theory. Principles, and Practice (pp. 118-134). St. Louis: Mosby-Year Book, Inc.

Jaffe, E. \& Epstein, C. (1992c). Toward a theoretical model of occupational therapy consultation. In E. Jaffe \& C. Epstein (Eds.). Occupational Therapy Consultation: Theory, Principles, and Practice (pp. 676-713). St. Louis: Mosby-Year Book, Inc.

Jaffe, E. \& Epstein, C. (1992d). The process of consultation. In E. Jaffe \& C. Epstein (Eds.). Occupational Therapy Consultation: Theory. Principles, and Practice (pp. 161-162). St. Louis: Mosby-Year Book, Inc. 
Kauffman, Nancy A. (1988). Occupational therapy in the school system. In H. Hopkins \& H. Smith (Eds.). Willard and Spackman's Occupational Therapy (p. 707). Philadelphia: J. B. Lippincott Co.

Knoff, H. M., McKenna, A., \& Riser, K. (1991). Toward a consultant effectiveness scale: Investigating the characteristics of effective consultants. School Psychology Review, 20, 81-96.

Kurpius, D. \& Fuqua, D. (1993). Fundamental issues in defining consultation. Journal of Counseling and Development, 71, 598-600. Kurpius, D., Fuqua, D., \& Rozecki, T. (1993). The consulting process: A multidimensional approach. Journal of Counseling and Development, $71,601-606$.

Lilly, M. S. (1979). Competency-based training. Teacher Education and Special Education, 2, 20-25.

McCormick, L. \& Lee, C. (1979). Public law 94-142: Mandated partnerships. American Journal of Occupational Therapy, 33, 586588.

Medway, F. (1982). School consultation research: Past trends and future directions. Professional Psychology, 13, 422-429.

Merryfield, S. (1991). The referral process. In W. Dunn, (Ed.). Pediatric Occupational Therapy: Facilitating Effective Service Provision (pp.3-8). New Jersey: Slack, Inc.

Muhlenhaupt, M. (1991). Components of the program planning process. In W. Dunn (Ed.). Pediatric Occupational Therapy: Facilitating Effective Service Provision (pp.125-136). New Jersey: Slack, Inc. 
Ottenbacher, K. (1982). Occupational therapy and special education: Some issues and concerns related to Public Law 94-142. American Journal of Occupational Therapy, 36, 81-84.

Randolph, D. \& Magee, J. (1984). Teaching consultant interview skills:

measuring student progress. Teaching of Psychology, 11, 242-243.

Regan, N. (1982). The implementation of occupational therapy services in rural school systems, American Journal of Occupational Therapy, 36, 85-89.

Ross, G. (1993). Peter Block's flawless consulting and the homunculus theory: Within each person is a perfect consultant. Journal of Counseling and Development,71, 639-641.

Royeen, C. \& Coutinho, M. (1991). The special education administrator's perspective. In W. Dunn (Ed.). Pediatric Occupational Therapy: Facilitating Effective Service Provision (pp.307-317). New Jersey: Slack, Inc.

Royeen, C. \& Marsh, D. (1988). Promoting occupational therapy in the schools. American Journal of Occupational Therapy, 42, 713-717. SAS Institute Inc. (1985). SAS Users Guide: Statistics, Version 5 Edition. Cary, NC: SAS Institute Inc.

West, J. \& Brown P. (1987). State departments' of education policies on consultation in special education: The state of the states. Remedial and Special Education, 8, 45-51. 
West, J. F. \& Idol, L. (1993). The counselor as consultant in the collaborative school. Journal of Counseling and Development, 71, 678-683.

West, J. F. \& Idol, L. (1987). School consultation (Part I): An interdisciplinary perspective on theory, models, and research. Journal of Learning Disabilities, 20, 388-408.

Whitworth, J. E. (1994). The shortage of occupational therapy and physical therapy personnel in schools: Implications and actions. American Journal of Occupational Therapy, 48, 367-370.

Zaffrann, R. (1979). Using the workshop in consultation training. Counselor Education and Supervision, 18, 304-311. 
Table 1

\section{Participant Demographics}

Distribution of Subjects

M

n

$\%$

Age $(N=44)$

32 yrs. or less

40.7

33-38 yrs.

$39-43$

44-48 yrs.

More than 48 yrs.

Work situation $(\mathrm{N}=43)$

Full time

26
15

Part time

Consultant only

2

$\begin{array}{ll}9 & 20.5 \\ 8 & 18.2\end{array}$

12

27.3

$8 \quad 18.2$

$7 \quad 15.9$

Gender ( $N=44)$

Female

Male

42

2

95.5

4.5

County in which subjects consult*

$(\mathrm{N}=32)$

Broward

Palm Beach

Dade

Lee

Manatee

Pasco

Pinellas

Brevard

Charlotte

Sumter

Nassau

Hillsborough

Walton

Orange

$\begin{array}{rr}8 & 25.0 \\ 5 & 15.6 \\ 3 & 9.4 \\ 2 & 6.3 \\ 2 & 6.3 \\ 2 & 6.3 \\ 2 & 6.3 \\ 1 & 3.1 \\ 1 & 3.1 \\ 1 & 3.1 \\ 1 & 3.1 \\ 1 & 3.1 \\ 1 & 3.1 \\ 1 & 3.1\end{array}$

"Note. $30.4 \%$ of subjects did not respond to this question 
Table 2

Participant Demographics

Distribution of Subjects

Years Employed $(\mathrm{N}=44)$

In profession

6 yrs. or less

7-11 yrs.

$12-16$ yrs.

17-21 yrs.

More than 21 yrs.

In schools

4 yrs. or less

5-8 yrs.

9-12 yrs.

More than 13 yrs.

In present setting

3 yrs. or less

4-6 yrs.

7-9 yrs.

More than $9 \mathrm{yrs}$.
13.8

$\begin{array}{cc}9 & 20.5 \\ 9 & 20.5 \\ 10 & 22.7 \\ 7 & 15.9 \\ 9 & 20.5\end{array}$

7.8

$\begin{array}{cc}13 & 30.2 \\ 14 & 32.6 \\ 10 & 23.3 \\ 6 & 14.0\end{array}$

5.5

$\begin{array}{cc}19 & 44.2 \\ 9 & 20.9 \\ 6 & 14.0 \\ 9 & 20.9\end{array}$

Degree and Certifications ( $N=44)$

Degree

AAS

BS

MS
1

30

12

36

3

2

1

1

Nursing

Special certifications

Neurodevelopmental

Sensory Integration

Pediatric Certification
$5 \quad 11.1$

$9 \quad 20.5$

$2 \quad 4.7$ 
Table 3

Occupational Therapists' Actual and Preferred Time Spent in Consultative Services

\begin{tabular}{lcc}
\hline $\begin{array}{l}\text { Time variable } \\
\mathrm{N}=46\end{array}$ & $\begin{array}{c}\text { Amount of time spent in } \\
\text { consultative services } \\
(\%)\end{array}$ & $\begin{array}{c}\text { Reported ideal amount of time to be } \\
\text { spent in } \begin{array}{c}\text { consultative services } \\
(\%)\end{array}\end{array}$ \\
\hline $\begin{array}{l}\text { Twice/day } \\
\text { Once/day }\end{array}$ & 0.0 & 4.3 \\
$3-5 \times /$ week & 30.2 & 4.3 \\
Twice/week & 16.3 & 15.2 \\
Once/week & 11.6 & 4.3 \\
Twice/month & 11.6 & 8.7 \\
Once/month & 11.6 & 4.3 \\
As needed & 0.0 & 2.2 \\
Other (not specified) & 18.6 & 56.5 \\
& & 0.0 \\
\hline
\end{tabular}


Table 4

With Whom Do Respondents Consult and How Often

\begin{tabular}{|c|c|c|c|c|c|c|c|}
\hline \multirow[t]{2}{*}{ Consultees } & \multirow[b]{2}{*}{0} & \multirow[b]{2}{*}{$1-5$} & \multicolumn{5}{|c|}{$\begin{array}{l}\text { Amount of time spent consulting } \\
\text { in hours per month } \\
\text { (\% of respondents in agreement) }\end{array}$} \\
\hline & & & $6-10$ & $11-20$ & $21-30$ & $31-40$ & $41-80$ \\
\hline Regular classroom teachers & 15.6 & 60.0 & 2.2 & 17.7 & 4.4 & 0.0 & 0.0 \\
\hline Special education teachers & 2.2 & 48.9 & 22.2 & 13.3 & 6.6 & 2.2 & 2.2 \\
\hline Family members & 20.0 & 55.6 & 11.1 & 11.1 & 0.0 & 2.2 & 0.0 \\
\hline Program administrators & 37.8 & 40.0 & 6.6 & 11.0 & 4.4 & 0.0 & 0.0 \\
\hline Physical therapists & 22.2 & 44.5 & 13.2 & 6.7 & 0.0 & 4.4 & 8.9 \\
\hline Speech/language therapists & 13.3 & 64.4 & 0.0 & 11.1 & 6.7 & 0.0 & 2.2 \\
\hline Other occupational therapists & 46.7 & 24.4 & 17.8 & 4.4 & 0.0 & 0.0 & 6.6 \\
\hline Outside agencies/professionals & 54.5 & 29.6 & 4.5 & 2.3 & 0.0 & 0.0 & 9.1 \\
\hline
\end{tabular}


Table 5

Primary Model of Consultation Used and Preferred by Respondents

Model

$(\mathrm{N}=46)$

Collaborative

Teacher/Counselor

No Particular Model Used

Expert

System/Organization Centered
Respondents Using the Model

(\%)
Respondents Preferring the Model

(\%)
52.8

33.3

11.1

2.8

0.0
73.0

10.8

10.8

2.7

0.0 
Table 6

Occupational Therapists Ratings of Relationships with Educators

OT Perceptions

$(\mathrm{N}=46)$

Respondents in Agreement (\%)

Do Educators Understand OT's Role?

Yes

$\mathrm{No}$

45.5

54.5

Quality of Relationships

Good

Fair

73.5

Poor

26.5

0.0

Level of Work Relationship

Adequate work

30.3

Reciprocal Work

27.3

Informed Work

24.2

Limited Work

24.2

No Relationship

6.1

Social Relationship Only

0.0 
Table 7

Perceived Barriers to the Consultation Process

Barriers

$(\mathrm{N}=46)$

very

Amount of Agreement (\%) somewhat

not

Inadequate time

51.2

37.2

11.6

Lack of intervention follow-through

20.5

70.5

9.1

by consultees

Severe staff shortage

36.4

29.5

34.1

Financial constraints

23.3

41.9

34.9

Physical barriers

17.8

42.2

40.0

Administration mismanagement

9.1

40.9

50.0

of roles

Lack of support/cooperation of teachers

8.9

60.0

31.1

Opposition by administration

0.0

37.8

62.2

Conflicts regarding procedures

0.0

40.9

59.1

Conflicts regarding setting goals

0.0

20.5

79.5

Philosophical differences regarding

6.7

51.1

42.2

treatment approaches

Philosophical differences regarding

2.2

40.0

57.8

clients' treatment

Personality conflicts

2.2

35.6

62.2

Philosophical differences regarding

0.0

20.9

79.1 assessment

Lack of consultant skills

4.7

30.2

65.1 
Table 8

Perceived Benefits of the Consultation Process

Benefits

$\%$ of Respondents in Agreement

Improved quality of treatment 74.4

Efficiency of treatment 70.5

Administration reinforcement 28.9

Professional activities enhanced 35.6

Opportunity for critical exchange of 82.6 information

Increased security regarding decision making 39.1

More follow-through of teachers 78.3

No perceived benefits

8.9 
Table 9

Roles Occupational Therapists Assume When Consulting

Roles

$(\mathrm{N}=46)$

Respondents in Agreement

(\%)

Joint Problem Solver

91.3

Professional

91.3

Information Specialist

89.1

Indirect Service Provider

80.4

Trainer/Educator

76.1

Peer

67.4

Facilitator

67.4

Advocate

64.4

Objective Observer/Reflector

57.8

Counselor/Advisor

56.5

Expert

45.7

Outsider

10.9 
Table 10

OT Respondents' Motivators for Engaging in Collaborative Consultation

Motivators

Respondents in Agreement

(\%)

Requests of Teachers

68.9

Self-Motivated

65.1

Children Need Less Treatment Time

Than Direct Service Provides

56.1

Part of Job Description

29.5

Set Up By Administration

7.3 
Table 11

Iraining received by OTs

Training Variable

$n$

$\%$

Amount of formal training received $(\mathrm{N}=28)$

None

Less than 1 semester

1 semester to 1 year

More than 1 year

5

13

6

2
17.9

46.4

21.4

7.1

Type of training received $(\mathrm{N}=28)$

Workshop

AOTA self-study course

Continuing education

Self-study

Undergraduate curriculum

Graduate education

Peer/supervisor training
13

13

11

7

6

5

2
46.4

46.4

39.3

26.9

20.7

17.2

7.4

Amount of informal training received $(\mathrm{N}=38)$

None

1 hour

Several hours

1 day

1 week

Ongoing
2

6

9

5

1

13
5.3

15.8

23.7

13.2

2.6

34.2

Perceived quality of training received $(N=38)$

Inadequate

Less than adequate

Adequate

More than adequate

Superior
2

6

20

10

0
5.3

15.8

52.6

26.3

0.0

Perceived importance of training to function as a consultant $(\mathrm{N}=38)$

Mildly important

Moderately important

Very important

Not important
18

13

12

0
41.9

30.2

27.9

0.0 
Table 12

OTs' Perceived Importance of Various Areas of Knowledge to Perform Consultation

\begin{tabular}{|c|c|c|c|}
\hline \multirow{2}{*}{$\begin{array}{l}\text { Areas of Knowledge } \\
\qquad N=46\end{array}$} & \multirow[b]{2}{*}{ very } & \multicolumn{2}{|c|}{ Amount of Agreement (\%) } \\
\hline & & somewhat & not \\
\hline Specialized inservice training on consultation & 28.9 & 66.7 & 4.4 \\
\hline Peer consultation groups & 43.2 & 45.5 & 11.4 \\
\hline Knowledge of occupational therapy & 85.7 & 14.3 & 0.0 \\
\hline Understanding of professional ethics & 62.8 & 34.9 & 2.3 \\
\hline Education and training in human development & 61.9 & 38.1 & 0.0 \\
\hline Education and training in group process & 39.0 & 51.2 & 9.8 \\
\hline Professional experience as a supervisor or manager & 18.4 & 55.3 & 26.3 \\
\hline Foundation in systems theory and behavioral sciences & 26.3 & 57.9 & 15.8 \\
\hline Foundation in developmental theory & 56.4 & 41.0 & 2.6 \\
\hline Knowledge of human personality & 58.1 & 38.7 & 3.2 \\
\hline
\end{tabular}


Table 13

Self-Perceived Consultation Skills

Consultation Skills

$(\mathrm{N}=46)$

inadequate < adequate adequate $>$ adequate superior

Ability to enter a school system

2.2

2.2

17.4

45.7

32.6

and establish a relationship

Diagnosis of problem/area to

0.0

0.0

29.5

59.1

11.4

be addressed with consultee

Ability to agree with consultee

0.0

4.4

26.7

62.2

6.7

in method of data collection

Ability to identify/recommend

2.2

2.2

45.7

43.5

6.5

resources for the consultee

Decision making skills

0.0

4.5

29.5

45.5

20.5

Defining therapists role in

0.0

2.3

40.9

38.6

18.2

the consultation process

Devising alternative plans

0.0

0.0

27.3

56.8

15.9

Terminating the consultative

0.0

17.8

46.7

33.3

2.2

relationship

Ability to give honest feedback

0.0

6.7

40.0

35.6

17.8

to teachers

Ability to monitor the consultee

0.0

13.3

42.2

35.6

8.9 
Correlations Between Consultation Models Used and Perceived Relationships with Educators

\begin{tabular}{|c|c|c|c|c|c|}
\hline \multirow{2}{*}{$\begin{array}{l}\text { OT Perceptions } \\
(\mathrm{N}=46)\end{array}$} & \multirow[b]{2}{*}{ Collaborative } & \multicolumn{2}{|c|}{ Model Used } & \multirow[b]{2}{*}{ None } & \multirow{2}{*}{$\begin{array}{l}\text { Fishers } \\
\text { exact test }\end{array}$} \\
\hline & & Expert & Teacher/Counselor & & \\
\hline \multicolumn{6}{|l|}{$\begin{array}{l}\text { Do Educators Understand } \\
\text { OT's Role? }\end{array}$} \\
\hline Yes & 18.75 & 3.13 & 15.63 & 9.83 & \multirow[t]{2}{*}{$p<.366$} \\
\hline No & 31.25 & 0.00 & 18.75 & 3.13 & \\
\hline \multicolumn{6}{|l|}{ Quality of Relationship } \\
\hline Good & 38.24 & 2.94 & 23.53 & 8.82 & \multirow{3}{*}{$\mathrm{p}<.896$} \\
\hline Fair & 11.76 & 0.00 & 11.76 & 2.94 & \\
\hline Poor & 0.00 & 0.00 & 0.00 & 0.00 & \\
\hline \multicolumn{6}{|c|}{ Level of Work Relationship } \\
\hline No Relationship & 3.03 & 3.03 & 0.00 & 0.00 & \multirow[t]{5}{*}{$\mathrm{p}<.403$} \\
\hline Limited Work & 9.09 & 0.00 & 3.03 & 0.00 & \\
\hline Adequate Work & 15.15 & 0.00 & 9.09 & 6.06 & \\
\hline Informed Work & 6.06 & 0.00 & 15.15 & 3.03 & \\
\hline Reciprocal Work & 18.18 & 0.00 & 6.06 & 3.03 & \\
\hline
\end{tabular}




\section{Survey of Occupational Therapists Employed by Florida Schools}

Please answer all of the questions completely and honestly to the best of your abiiity.

Please return to:

Leigh Ann Agee

6396 Manor Lane \#14 Miami, FL 33143

Please return by

\section{Date}

Name of school system (optional)

Is your school system Present age Sex urban suburban rural

Years employed in profession___ Years employed in the schools

Years employed in present setting

Full time Part time Specia! Certifications: NDT Highest degree held Other degrees held
Consultant only In what field?
SI__ Pediatric certification 
4. Ideal amount of time you would like to spend in consultation
a. twice a day
e. once a week
b. once a day
c. 3-5x/week
d. twice a week
h. as needed per child
g. once a month
i. other (please specify)

5. Approximate amount of time spent in consultation per child
a. once every two months
d. once a week
b. once a month
c. once every two weeks
e. twice a week

6. Does interdisciplinary planning and interaction occur on a consultation basis?
a. yes
b. no

7. With whom do you consult? (circle all that apply)
a. regular classroom teachers
b. special education teachers
c. farnily members
d. program administrators
e. physical therapists
f. speech/language therapists
g. other occupational therapists
h. outside agencies/ professionals

\# of hours per month spent with each

8. How often do you engage in interdisciplinary cooperative planning and treatment outside of the consultative process?
a. once a week
b. twice a month
c. once a month
d. once every two months
e. iwice a year
f. once a year
g. never
h. other (please specify)

9. Do you also provide direct treatment within the school system?
a. yes
b. no

10. What services do you believe are needed most to meet student needs?
a. direct service
b. collaborative consultation
c. both

11. Does your school system use a standardized evaluation to determine who receives consultative services?
a. yes
b. no 
12. Do you teel a standardized evaluation should be used?
a. yes
b. no

13. Choose the primary model of consultation you use: (choose one)

a. collaborative (interactive process in which two individuals contribute equally to mutualily defined problems)

b. expert (the consultant provides the solutions and the consultee is the recipient with no active roie)

c. teacher/counselor consultant gives advice or educates the consultee on issues of concein)

d. system/organization centered (focuses on the system and facilitating change within it)

e. no particular model used

14. Type of consultation you prefer to engage in with educators (using definitions as in \#13)
a. collaborative
b. expert
d. system/organizationa!-centered
€. no particular model
c. teacher/counselor
f. other

15. Do you feel the educational staff understands the role of OT in the school setting?
a. yes
b. no

16. How would you rate your relationship with teachers?
a. good
b. fair
c. poor

17. Please choose the level of relationship between yourself and the majority of teachers you consult with ${ }^{* * *}$ choose only one

A. Level 1 No relationship- consultee is hostile, indifferent, apathetic or have had no previous contact with the consultee

B. Level 2 Social relationship only-informal, social contact with the consultee, don't readily engage in discussion of work-related issues

C. Level 3 Limited work relationship-consultee asks for help but does not follow through, may be defensive or consultee readily engages in discussion of problems when approached but does not effectively participate in the development and implementation of problem solutions

D. Level 4 Adequate work relationship- consultee is open to consultantinitiated contact concerning problems and cooperates in the development and implementation of problem solutions

E. Level 5 informed work relationship-consultee initiates contact when a potential problem is identified and effectively participates in the development and implementation of problem solutions 
F. Level 6 Reciprocal work relationship-consultee seeks consultation when needed, is an active advocate for consuliation to other potential consultees

Additional comments

18. Roles you assume when consulting in the school system:

(check all that apply)

indirect service provider

-

information specialist

counselor/ adviser

objective observer/ reflector

joint problem solver

expert

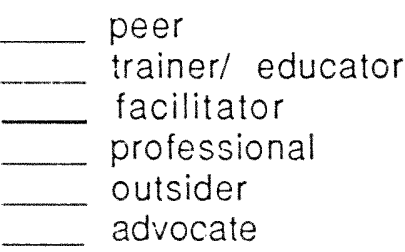

19. To what extent have you found the following to be a barrier to the consultation process?

\begin{tabular}{|c|c|c|c|}
\hline & ery & somewhat & not \\
\hline A. inadequate time for consultation.... & 1 & 2 & 3 \\
\hline B. lack of intervention follow-through by consultees................. & 1 & 2 & 3 \\
\hline 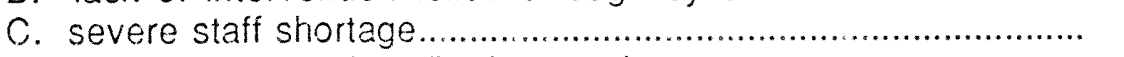 & 1 & 2 & 3 \\
\hline 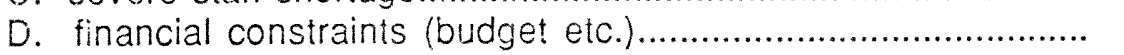 & 1 & 2 & 3 \\
\hline E. physical barriers (different schools, buildings) ................... & 1 & 2 & 3 \\
\hline F. administration mismanagement of roles.............................. & 1 & 2 & 3 \\
\hline G. lack of support, cooperation by teachers.............................. & 1 & 2 & \\
\hline 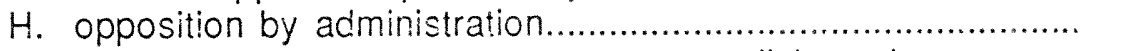 & 1 & 2 & 3 \\
\hline 1. conflicts regarding procedures to accomplish goals................ & 1 & 2 & 3 \\
\hline 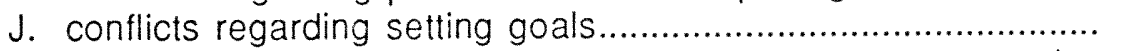 & 1 & 2 & \\
\hline K. philosophical differences regarding best treatment approach.. & 1 & 2 & 3 \\
\hline L. philosophical conflicts regarding clients' treatment................ & 1 & 2 & 3 \\
\hline 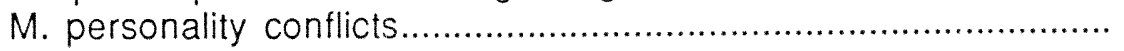 & 1 & 2 & 3 \\
\hline N. philosophical differences regarding assessment...................... & 1 & 2 & 3 \\
\hline O. lack of consultant skills................................. & 1 & 2 & \\
\hline
\end{tabular}

20. What are the benefits of collaborative consultation?

(check all that apply)

improved quality of treatment

efficiency of treatment

administration reinforcement

professional activities enhanced

opportunity for critical exchange of information

increased security regarding decision making

no perceived benefits

more follow-through of teachers 
21. What are your motivators for engaging in consultation services with teachers? (you may choose more than one)
a. seif-molivated
b. part of job description
c. set up by administration
d. requests of teachers
e. children need less treatmerit time than direct service provides

22. How well prepared do you feel to provide consultative services?
a. very well prepared
c. poorly prepared
b. adequately prepared
d. not at all prepared

23. Have you ever received formal training on how to be an effective consultant? a. yes b. no

24. If yes, through what means?
a. undergraduate curriculum
b. continuing education
c. self-study
d. peer/supervisor training
e. graduate education
f. workshop
g. AOTA self-study course on school-based OT services
h. other

25. How much formal training have you received?
a. none
$b$. less than one semester
c. one semester to one year
d. more than one year
e. other

26. How much informal training have you received?
a. none
b. one hour
c. several hours
d. one day
e. one week
f. ongoing
g. other

27. How would you rate the quality of training you received?
a. inadequate
b. less than adequate
c. adequate
d. more than adequate
e. superior

28. How important do you feel training is to function as a consultant?
a. not at all imforiant
b. mildly important
c. moderately important
d. very important 
29. How important are the following for consultation?

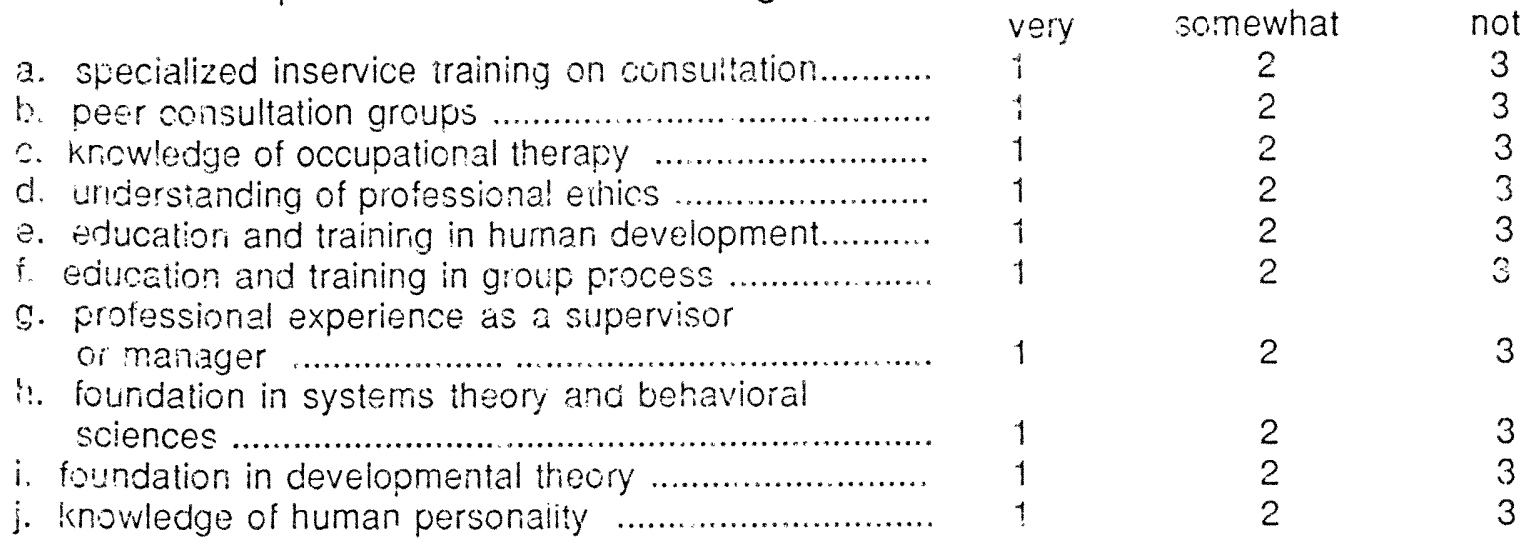

30. Rate your abilites in the following areas in the educational setting: inadequate adequate superior
A. Ability to enter a school system and establish a relationship
B. Diagnosis of problem/area to be addressed with consultee (teacher)
C. Ability to agree with consuitee in method of catá collection
D. Ability to identify and recommend resources for the consultee
E. Decision making skills
F. Defining your role/responsibilities in the consultation process
G. Devising alternative plans
$H$. Terminating the consultative relationship
1. Ability to give honest feedback to teachers
J. Ability to monitor the consultee

$\begin{array}{lllll}1 & 2 & 3 & 4 & 5 \\ 1 & 2 & 3 & 4 & 5 \\ 1 & 2 & 3 & 4 & 5 \\ 1 & 2 & 3 & 4 & 5 \\ 1 & 2 & 3 & 4 & 5 \\ 1 & 2 & 3 & 4 & 5 \\ 1 & 2 & 3 & 4 & 5 \\ 1 & 2 & 3 & 4 & 5 \\ 1 & 2 & 3 & 4 & 5 \\ 1 & 2 & 3 & 4 & 5\end{array}$
and changes as they occur as a result of the consultation process

31. Do you feel collaborative consultation is an effective treatment method for the school setting?
a. yes
b. no

32. Will you use it in the future?
a. yes
b. no

If you would like a copy of the results of this study please give your name and address here: 
Survey Cover Letter

August 5, 1994

Dear fellow occupational therapist:

As an occupationa! therapist providing services in the Florida school system, your help is needed. The shortage of occupational therapists in this araa has called for the need to examine what service provision models are boing used by therapists and how they perceive their role.

I am a professional masters degree occupational therapy student at Florida International University. I am conducting a study titled "Occupational therapists as consultants in the Florida schools" as part of my thesis to examine the issues surrounding consultation in the schools.

If you are currently providing consultation services within the school system in any capacity, please take 10 minutes of your time to complete the enclosed questionnaire. If you are not, please return the survey anyway indicating the reason for not completing it.

You may be assured of complete confidentiality. Providing your name on the questionnaire is optional. An ID number has been added for mailing purposes only. This is so I may check your name off of the mailing list when your questionnaire is returned. Your name wil! never be placed on the questionnaire if you do no: provide it.

For the purposes of this study collaborative consultation is defined as:

"a collaborative problem solving process that acknowledges the expertise of the consultant and the consultee, in which both share responsibility for identifying the problem, creating and trying solutions, but the consultee (teacher) is primarily responsible for implementing the plan, while the therapist provides services to the client (child) through indirect means."

The results of this study will provide important information on occupational therapists' perceptions of the consultation process 
within the public school system. Please take the time to contribute to this information. I would be happy to answer any questions you may have and may be contacted at the address listed on the top of the survey. Please return the survey by September 5, 1994 or as soon as possible.

Thank you for your assistance.

Sincerely,

Leigh Ann Agee 